\title{
Ultrasound Assessment of Low Risk Versus High Risk Pregnancy and Perinatal Outcome
}

\author{
Rita Thakur, M.D', Rabia Khurshid, M.D², Swarn Kanta Gupta, M.D³, Cimona Lynsandanha, M.D4, \\ Abida Ahmad, M.D ${ }^{5}$ \\ ' Lecturer, Department of OBG, GMC, Jammu, ${ }^{2,4}$ Assoc. Professor, Deptt. of OBG, SKIMS, Srinagar \\ ${ }^{3}$ Asst. Professor, Department of OBG, GMC Jammu, ${ }^{4}$ Professor, Department of OBG, SKIMS, Srinagar
}

\section{A B S T R A C T}

Objective: To determine the maturational changes in placenta by ultrasonography at various gestational ages in low risk versus high risk pregnancies and their correlation with perinatal outcome.

Subjects: Study was conducted in 100 patients with singleton pregnancies, divided into two groups: Group A (control group) having no medical or obstetrical complications in the current pregnancy and Group B (study group) having medical or obstetrical complication. All the patients were subjected to ultrasonography between 28-31 weeks, 32-37 weeks and after 37 weeks of gestation. All cases were followed till pregnancy outcome and neonates followed upto 7 days after birth. Perinatal outcome of group Aand group B was compared.

Results: It was observed that placental maturity increased with gestational age in both groups but placenta matured earlier in high risk cases. $8 \%$ patients in group $A$ and $26 \%$ in group B showed earlier placental maturation. Patients of diabetes mellitus showed delayed maturity and low grades were found even at termination. Incidence of LSCS was $44 \%$ in group B and $20 \%$ in group A. Good apgar score was shown when placental maturity was of higher grade. Respiratory distress syndrome was seen in only $6.8 \%$ neonates in group Aand $14.2 \%$ in group B at termination with grade III placenta. 19\% neonates in group A required admission to an ICU as compared to $37 \%$ in group B. Perinatal mortality was high in patients who had placental grade 0 and 1 at termination in both the groups. There was $10 \%$ perinatal mortality ( $4 \%$ still births and $6 \%$ neonatal deaths) in group $A$ and $14 \%$ (4\% still births and $10 \%$ neonatal deaths) in group $B$ as high risk patients were there in group $B$.

Conclusion: Placental grading by ultrasonography is a reliable index of foetal pulmonary maturity and it can assist the obstetrician in the management of high risk patients, thus making ultrasonography a useful tool for predicting the perinatal outcome and planning treatment modalities for termination of pregnancy. JMS 2014; 17 (1): 6-10

Keywords: Ultrasound, placental maturity, perinatal outcome.

\section{INTRODUCTION}

The antenatal assessment of foetal maturity is necessary whenever a non-emergent caesarean section or induction of labour is contemplated. This is particularly true in high risk pregnancies in which termination is desired at the earliest time conductive to infant survival. Ultrasound provides a non-invasive technique for the evaluation of foetal gestational maturity. Histologic and morphologic features of placenta show characteristic changes that can be correlated with advancing gestational age.

Numerous studies documented sonographic changes in

\section{Correspondence}

Dr. Rabia Khurshid, M.D

Assoc. Professor, SKIMS.

Email ID: rabia.khurshid@skims.ac.in both normal and complicated pregnancies. Tindal et al $(1965)^{1}$ first described calcification, occurring in most placentae, that increased in number towards term. Quinlan et al $(1982)^{2}$ found the association of premature appearance of grade III changes in the placenta in complicated pregnancies which suggests that these changes are associated with decrease in placental function and premature senescence of the placenta.

Grade III placenta was associated with delivery of "small for gestational age" infants and ultrasonography placental grading can be used to discriminate those with or without $\mathrm{IUGR}^{3}$.

Agarwal and Jain (2000) ${ }^{4}$ suggested that the placental grading advanced with the gestational age in both low and high risk pregnancies but in patients with hypertension and 
IUGR placental maturity was accelerated being higher than normal pregnancy of similar gestational age. Patients of diabetes mellitus showed delayed maturity of placenta and lower grades were found even in patients approaching term. Placental maturity showed a direct correlation with pulmonary maturity. Respiratory distress syndrome never developed when placenta was grade III.

The present study was undertaken to determine the maturational changes in the placenta at various gestational ages in low risk vs high risk pregnancies and their correlation with perinatal outcome.

\section{METHODS}

A total of hundred patients selected for the study were carrying a singleton pregnancy from 28 weeks of gestation onwards and were followed till pregnancy outcome.

Selected cases were divided into two equal groups:

Frist group (Control Group - Group A): This comprised of 50 patients with singleton pregnancies, having no medical or obstetrical complications in the current pregnancy.

Second group (Study group Group B): This comprised of 50 patients with singleton pregnancies, having medical or obstetrical complications like pregnancy induced hypertension, IUGR, anemia, diabetes mellitus, hypertension, antepartum haemorrhage and postdatism in current pregnancy.

Detailed clinical evaluation was done including history, examination, routine investigations and ultrasonography.

Ultrasonographic studies were performed by ultrasonologist with the use of 3.5 to $5 \mathrm{MHz}$ linear or sector transducer on real time gray scale sonographic scanner. All the patients were subjected for ultrasonography between 28-31 weeks, 32-37 weeks and after 37 weeks gestation. Data from all ultrasonographic examination were recorded with reference to following:

Morphometric measurements including BPD, Femur length, gestational age, amount of liquor, foetal heart pulsations, placental localization, grade/ calcifications/ degenerations, any congenital anomaly.

UGS abnormalities like intrauterine clot, placenta praevia and retroplacental haematoma were also noted.

All the cases were followed until delivery. Outcomes were recorded from a comprehensive perinatal database maintained within department of obstetrics and gynecology.

Outcome of interest were:

- Gestational age at delivery.

- Labour (spontaneous or induced).

- Delivery outcome ( normal vaginal delivery or caesarean section)

- $\quad$ Still birth, condition of infant at birth including birth weight, apgar score, respiratory distress syndrome, early neonatal death (0-7 days), neonatal intensive care admissions and foetal growth restriction.

Statistical analysis was performed and pregnancy outcome variables of two groups compared.

\section{OBSERVATIONS}

The present study comprised of 100 women with pregnancy beyond 28 weeks of gestation divided into two equal groups.

Differences between the two groups regarding maternal age, parity and socioeconomic status were statistically insignificant. Maximum no. of patients were found in age group 25-29 years in both groups. 50\% of patients in group A and $48 \%$ in group B were found in this age group. 58\% of patients in group A and 54\% in group B were multiparas.

Maximum no. of patients in both groups belong to social class III \& IV. $60 \%$ \& $78 \%$ of patients were found in social class III \& IV in group A \& B respectively.

Placental maturity increased in both groups but placenta matured earlier in high risk cases (i.e. PIH, hypertension and IUGR). In group A, grade III placental maturity was seen at 32-37 weeks of gestational age in $8 \%$ cases in contrast to $26 \%$ cases in group B.

High risk factors were: PIH (10), hypertension (4), postdatism (7), APH (11), DM (4), IUGR (4), BOH (4). It was observed that placental maturity was accelerated in patients with PIH, hypertension and IUGR but delayed in diabetes mellitus. None of patients of diabetes mellitus, $\mathrm{BOH}$ and anaemias showed grade III placental changes at term.

In patients with $\mathrm{APH}, 36 \%$ patients showed grade III maturity at term. 
Table I: Relation of early placental maturation with foetal complications

\begin{tabular}{|c|c|c|c|c|c|c|c|}
\hline \multirow{2}{*}{$\begin{array}{l}\text { Gestational age } \\
\text { (in weeks) }\end{array}$} & \multirow[b]{2}{*}{ Groups } & \multirow{2}{*}{$\begin{array}{l}\text { No. of } \\
\text { cases } \\
\text { with \% }\end{array}$} & \multicolumn{5}{|c|}{ Foetal complications } \\
\hline & & & IUGR & \begin{tabular}{l|l} 
Foetal \\
Distress
\end{tabular} & $\begin{array}{l}\text { Neonatal } \\
\text { Jaundice }\end{array}$ & $\begin{array}{l}\text { Still } \\
\text { Birth }\end{array}$ & $\begin{array}{l}\text { Neonatal } \\
\text { death }\end{array}$ \\
\hline \multirow{2}{*}{$28-31$} & Group A & - & - & - & - & - & - \\
\hline & Group B & - & - & - & - & - & - \\
\hline \multirow{2}{*}{$32-37$} & Group A & $4(8)$ & 1 & 1 & - & - & - \\
\hline & Group B & $13(26)$ & 4 & 2 & 2 & 1 & - \\
\hline
\end{tabular}

Early placental maturation (grade III placental maturation before 37 weeks of gestation) in $8 \%$ cases in group $\mathrm{A}$ in contrast to $26 \%$ in group B majority of which were associated with foetal complications as shown in table I.

TABLE-II: DISTRIBUTION OF PATIENTS ACCORDING TO MODE OF DELIVERY

\begin{tabular}{|l|l|l|l|l|l|}
\hline \multirow{2}{*}{ Type of Delivery } & \multicolumn{2}{|c|}{ Group A } & \multicolumn{2}{c|}{ Group B } & \multirow{2}{*}{ p-value } \\
\cline { 2 - 5 } & $\begin{array}{l}\text { No. of } \\
\text { Patients }\end{array}$ & $\%$ & $\begin{array}{l}\text { No. of } \\
\text { Patients }\end{array}$ & $\%$ & \\
\hline Vaginal Delivery & 40 & 80 & 28 & 56 & \multirow{2}{*}{$0.018^{*}$} \\
\hline Caesarian Section & 10 & 20 & 22 & 44 & \\
\hline Total & 50 & 100 & 50 & 100 & \\
\hline
\end{tabular}

$$
\text { * - Significant }
$$

While $80 \%$ patients in group A and $56 \%$ in group B delivered vaginally. Caesarean section rate was higher in group B (44\%) as compared to group A (20\%). This difference was significant.

Table III: Relation of placental grading with apgar score of neonates at birth

\begin{tabular}{|c|l|l|l|l|l|l|}
\hline \multirow{2}{*}{$\begin{array}{c}\text { Placental } \\
\text { grading }\end{array}$} & \multicolumn{6}{|c|}{ Apgar score at birth } \\
\cline { 2 - 7 } & $0-3$ & $4-6$ & $7-10$ & $0-3$ & $4-6$ & $7-10$ \\
\hline 0 & - & - & - & - & - & - \\
\hline I & 1 & - & - & 1 & 1 & 1 \\
\hline II & 1 & 5 & 14 & - & 7 & 11 \\
\hline III & 0 & 2 & 27 & 1 & 2 & 26 \\
\hline
\end{tabular}

In group A, out of 21 patients with placental grade I and II, at term 7 neonates had apgar score $<7$ and 14 neonates had $>7$ as compared to group B, 9 neonates had apgar score $<7$ and 12 had $>7$. Good apgar score was seen with grade III maturity at termination in both groups as shown in table III.

Table IV: Relation of placental grading with development of respiratory distress syndrome

\begin{tabular}{|c|c|c|c|c|c|c|c|}
\hline \multirow{4}{*}{$\begin{array}{l}\text { Placental } \\
\text { grading }\end{array}$} & \multicolumn{6}{|c|}{ Respiratory distress } & \multirow[t]{4}{*}{ P-VALUE } \\
\hline & \multicolumn{3}{|c|}{ Group A } & \multicolumn{3}{|c|}{ Group B } & \\
\hline & \multirow{2}{*}{$\begin{array}{l}\text { Total No. of } \\
\text { patients }\end{array}$} & \multicolumn{2}{|l|}{ RDS } & \multirow{2}{*}{$\begin{array}{l}\text { Total No. of } \\
\text { Patients }\end{array}$} & \multicolumn{2}{|c|}{ RDS } & \\
\hline & & tve & -ve & & +ve & -ve & \\
\hline 0 & 0 & 0 & 0 & 0 & 0 & 0 & - \\
\hline I & 0 & 0 & 0 & 2 & 2 & 0 & - \\
\hline II & 19 & 6 & 13 & 18 & 7 & 11 & 0.903 \\
\hline III & 29 & 2 & 27 & 28 & 4 & 24 & 0.442 \\
\hline
\end{tabular}

Incidence of respiratory distress was higher in group B (high risk group), (27.0\%) as compared to group A (16.6\%). $6.8 \%$ neonates of the patients with grade III placental maturity at termination developed RDS in group $\mathrm{A}$ as compared to $14.2 \%$ in group B as shown in Table IV. The differences are not statistically significant.

TABLE -V: Relation of Placental Grading at Term with Perinatal Mortality

\begin{tabular}{|l|l|l|l|l|l|l|l|l|l|l|l|}
\hline \multirow{2}{*}{$\begin{array}{c}\text { Placental } \\
\text { Grading }\end{array}$} & $\begin{array}{c}\text { Total No. } \\
\text { of Cases }\end{array}$ & S.B. & $\%$ & N.D. & $\%$ & $\begin{array}{c}\text { Total No. } \\
\text { of Cases }\end{array}$ & S.B. & $\%$ & N.D. & $\%$ \\
\hline 0 & - & - & - & - & - & - & - & - & - & - \\
\hline I & 1 & 1 & 2 & 0 & 0 & 3 & 1 & 2 & 1 & 2 \\
\hline II & 20 & 1 & 2 & 2 & 4 & 18 & 0 & 0 & 1 & 2 \\
\hline III & 29 & - & - & 1 & 2 & 29 & 1 & 2 & 3 & 6 \\
\hline
\end{tabular}

The above table reflects that patients with placental grade I at termination showed high perinatal mortality in both groups. Whereas patients with placental grade II and III maturity at term showed $8 \%$ mortality in group $\mathrm{A}$ as compared to $10 \%$ in group B. Overall mortality in group A was $10 \%$ (4\% still births and $6 \%$ early neonatal deaths) as compared to $14 \%$ (4\% still births and $10 \%$ early neonatal deaths) in group B.

\section{DISCUSSION}

The risk of certain adverse perinatal outcome is significantly increased among patients showing higher grades of placental maturity before 37 weeks of gestation. Detection of higher grades by ultrasound early in third trimester can alert the obstetrician for close observation regarding development of PIH, IUGR, abruptio placentae, foetal distress and perinatal outcome. Detection of placental maturity by ultrasonography makes ultrasonography a useful tool for predicting the livelihood of poor outcome.

In the present study it was observed that age, parity and socioeconomic status has no impact as risk factors in any of the groups.

We correlated placental maturation with gestational age in both the groups and found that grade I, II and III placental maturation was present in $2 \%, 40 \%$ and $58 \%$ of cases respectively at term in control group and in study group, this incidence was $6 \%, 26 \%$ and $58 \%$ respectively. Placental grade III was present in $8 \%$ of cases in group A in contrast to $26 \%$ of cases in group B, before 37 weeks of gestation thereby indicating an early maturation of placenta in high risk cases like PIH, hypertension and IUGR. These observations are almost similar to those reported by Agarwal and Jain (2000) ${ }^{4}$. They found that at term in control group, placental grades I, II and III were present in 6\%, 46\% 
and $47 \%$ of cases respectively and this incidence was $0 \%$, $33 \%$ and $66 \%$ respectively in high risk group. Before 37 weeks of gestation, grade III placental maturation was 30\% in high risk cases and $25 \%$ in low risk cases.

Placental maturation in PIH, hypertension and IUGR is accelerated which might be a result of uteroplacental ischaemia due to abnormal vasospasm of uterine vessels leading to hypoxia, necrosis, haemorrhage in placenta and placental insufficiency. We found the incidence of early placental maturation in patients with PIH, IUGR and hypertension was $50 \%, 50 \%$ and $75 \%$ respectively which is in consonance with Hills (1994) ${ }^{5}$ study in which accelerated placental maturation was found in 38\% and 53\% in PIH and IUGR cases respectively. Agarwal and Jain (2000) ${ }^{4}$ observed accelerated placental maturation in $63 \%$ of cases with hypertension and $42 \%$ with IUGR.

In contrast to accelerated placental maturation in above mentioned cases, placental maturation is delayed in patients with diabetes mellitus. It may be related to the foetal biochemical and morphologic development.

We found out of 4 patients with diabetes mellitus, 3 patients had grade I and II placental maturation at term whereas none of the patients had grade III placental maturation even at term. These findings are in agreement with those of Roy and Roy (1994) $)^{6}$. They demonstrated that out of 9 cases of diabetes mellitus, none had grade III placental maturation even at termination. A lag in placental maturity in diabetes mellitus at termination was also observed by Granum et al (1979) ${ }^{7}$, Harman and Maning (1982) ${ }^{8}$ and Agarwal and Jain $(2000)^{4}$. Presence of grade O placenta after 32 weeks of gestation should arouse suspicious of diabetes mellitus and a glucose tolerance test should be performed.

Early placental maturation is associated with increased incidence of foetal complications like IUGR, foetal distress, neonatal jaundice, still birth and neonatal deaths. We observed that the incidence of early maturation in group A was $8 \%$ in contrast to $26 \%$ in group B. intrauterine growth retardation was present in $25 \%$ neonates, foetal distress in $25 \%$ and neonatal deaths in $25 \%$ cases in group B, whereas this incidence was $31 \%, 25 \%$ and $23 \%$ respectively in group A. Our observations are comparable to those of Agarwal and Jain (2000) $)^{4}$ who observed early placental maturation in $25 \%$ in low risk cases and $30 \%$ in high risk cases.
$80 \%$ patients in group A and $56 \%$ in group B had normal vaginal delivery whereas, $20 \%$ cases in group A and $44 \%$ in group B delivered by LSCS. This difference was statistically significant $(\mathrm{p}<0.01)$. Rangozzino et al (1983)9 also observed high rate of caesarean section in high risk cases. In their study $56 \%$ of high risk patients delivered by caesarean section and $44 \%$ delivered vaginally.

In group A, patients with placental grade I and II had 33\% neonates with Apgar score $<7$ and $66 \%$ with $>7$ whereas in group B these figures were $42 \%$ and $57 \%$ respectively. Our observations are comparable to those Agarwal and Jain $(2000)^{4}$.

Respiratory distress syndrome developed in $16.6 \%$ and $27.0 \%$ neonates in group A and group B respectively. High incidence of respiratory distress syndrome in group B could be explained due to high incidence of RDS in neonates of mothers with diabetes mellitus. In group A RDS was seen in $6.8 \%$ neonates with grade III placenta at term in contrast to $14.2 \%$ neonates in group B. Our figures are higher than those reported by various authors Kazzi et al $(1985)^{10}$, Roy and Roy (1994) $)^{6}$, Agarwal and Jain (2000) ${ }^{4}$. This could be due to high rate of caesarean section in group B (44\%)and RDS occurs commonly in babies delivered by LSCS.

$19 \%$ neonates with low apgar score required admission to neonatal intensive care unit in group A as compared to $37 \%$ in group B. Statistically significant difference $(\mathrm{p}<0.05)$. This could be explained because of more number of babies with low apgar score at birth in group B. Neonates of mothers with placental grade I at term had high perinatal mortality in both the groups whereas, patients with placental grade II and III together had $8 \%$ perinatal mortality ( $2 \%$ still births and $6 \%$ neonatal deaths) in group A and $10 \%$ perinatal mortality (2\% still births and $8 \%$ neonatal deaths) in group B.

On the whole perinatal mortality in our study was $12 \%$ and is in consonance with those observed by Roy and Roy (1994) 7\% and Aggarwal and Jain (2000) 11\%. High perinatal mortality in group B could be explained because group B comprised of patients with hypertension, diabetes, APH and IUGR. Small for date infants associated with maternal hypertension have a perinatal mortality rate eight times higher than that of babies (Hobbin, 1980) ${ }^{11}$ whose weight is appropriate for gestational age. They are at high 
risk of developing asphyxia during labour.

It was observed that still births were equal in both the groups (4\%). Early neonatal deaths were less $(6 \%)$ in group A as compared to group B $(10 \%)$. Overall perinatal mortality was $10 \%$ in group A and $14 \%$ in group B, inspite of the fact that the patients of group B were admitted to the hospital earlier and good antenatal care was provided to them.

It is concluded that placental grading by ultrasound is a safe, non-invasive and reliable index of foetal pulmonary maturity and the presence of grade III placenta before 37 weeks of gestation requires close monitoring with continuation of pregnancy. Patients with high risk pregnancies should be referred to a hospital having facilities of ultrasonography and an adequate neonatal intensive care unit. Neonates requiring admissions to an ICU need to have a long term follow up to rule out mental retardation, learning disabilities and neurological abnormalities in later life.

\section{REFERENCES}

1. Tindal VR. Placental calcification a study of 3025 singleton and multiple pregnancies. J Obst and Gynae Br C'wealth 1965; 72: 356-372.

2. Quinlan W, Amella C and Cruze. Ultrasonic placental grading and foetal maturity. Am J ObstGynaecol 1982; 142: 110-112.

3. Altshuler G, Russel P, Ermocilia R. The placental pathology of small-for-gestatioinal-age infants. Am J ObstGynaecol 1975; 121: 351.
4. Agarwal V and Jain S. Placental grading and its correlation with foetal outcome. J ObstGynaecol India 2000; 50: 59-62.

5. Hills Dona, Irwin GAL, Tuck S, Baim R. Distribution of placental grade in high risk gravidas. Am J Roentegenol 1984; 142: 1011.

6. Bula R and Shanti R. Clinical significance of placental grading by Sonar. J ObstGynaecol India 1994; 44: 343348.

7. Granum PAT, Berkowitz RL, Hobbins JC. The ultrasonic changes in the maturing placenta and their relation to foetal pulmonic maturity. Am J ObstGynaecol 1979; 133: 915.

8. Harman CR, Manning FA, Stearns E, Marrison. The correlation of ultrasonic placental grading and foetal pulmonary maturation in 563 pregnancies. Am J ObstGynaecol 1982; 143: 941.

9. Rogozzino, Lynden M and Breckle R. The relationship of placental grade by ultrasound to markers of foetal lung maturity. Radiology 1983; 148: 805-807.

10. Kazzi GM, Gross TL, Sokol RJ. Non-invasive prediction of hyaline membrane disease: an optimized classification of sonographicplacental maturation. Am J ObstGynaecol 1985; 152: 213. 